\title{
Commentary
}

\section{CAM and Post-Traumatic Stress Disorder}

\author{
Alex Hankey \\ Health Sciences, University of Pune, Maharashtra, India
}

\begin{abstract}
In the form of the Transcendental Meditation program CAM offers a method of eliminating deep-rooted stress, the efficacy of which has been demonstrated in several related studies. Any discussion of CAM and post-traumatic stress disorder should include a study of its application to Vietnam War Veterans in which improvements were observed on all variables, and several participants were able to return to work after several years of being unable to hold a job. The intervention has been studied for its impact on brain and autonomic nervous system function. It has been found to be highly effective against other stress-related conditions such as hypertension, and to improve brain coherence- a measure of effective brain function. It should be considered a possible 'new and improved mode of treatment' for PTSD, and further studies of its application made.
\end{abstract}

Keywords: ayurveda - post-traumatic stress disorder - transcendental meditation

\section{Introduction}

The paper in your November 2005 issue, 'Post-Traumatic Stress Disorder: Evidence-Based Research for the Third Millennium', by Iribarren and co-workers (1), contained many pertinent references and very useful discussion. It did not, however, propose more than palliative care to PTSD sufferers, reducing discomfort, but not the helplessness, trials and tribulations of long-term chronic disease management.

Had it included a study on Vietnam war veterans at the Denver Vietnam Veterans Outreach Program in 1981 (2), this might have been different. The study's authors reasoned that since, in previous studies of the Transcendental Meditation ${ }^{\mathrm{TM}}$ program (TM) (Transcendental Meditation and TM are service marks registered in the US Patent and Trademark Office, licensed to Maharishi Vedic Education Development Corporation, and used under sublicense), many of the symptoms of post-Vietnam Adjustment had been seen to reduce (see below), veterans with PVA should improve. In their study, 28 veterans were randomized between two groups, one of which received normal psychotherapy and the other, the TM program. Eight in the psychotherapy group completed the study and 10 in the TM group. Measurements were made before and after a

For reprints and all correspondence: Alex Hankey, Hethe House, Cowden Kent TN8 7DZ, UK. Tel: +44 1342 850086; E-mail: Alexhank@dircon.co.uk
3 month experimental period of delayed stress syndrome, anxiety, depression (Fig. 1), insomnia, alcohol use, family problems, employment status and GSR habituation to a stressful stimulus. Improvements were seen on all measures for the TM group, with $P$-values ranging from 0.05 to 0.001 , except for GSR's where improvement only reached $P<0.10$, requiring either more time or more subjects to reach $P<0.05$ if the same trend had been maintained. By comparison, no similar changes were observed in the psychotherapy group: deep rooted stress of the kind encountered in war induced PTSD, 'shell shock', can be difficult to resolve by conventional means, as evidenced by Iribarren et al. (1).

In the Denver study (2), the particular form of PTSD, post-Vietnam adjustment was observed to reduce from $9.70 \pm$ 2.98 to $5.80 \pm 4.26, P<0.001$ for the paired, one tailed $t$-test, pre and post. After the 3 month experimental period, 7 out of the 10 of those who had participated in the Transcendental Meditation program felt so much improved that they decided they no longer needed the Veteran's Center services. The remaining three decided to continue with a combination of TM and therapy-indicating increased hope and belief that they too could recover. Personal impressions of the effects of TM as an intervention included the report, 'I feel after I meditate that I no longer have the same burden of tension, rage and guilt inside-it's as if a huge burden has been lifted.' It should be added that for TM 3 months is a short period over which to

(C) The Author (2006). Published by Oxford University Press. All rights reserved.

The online version of this article has been published under an open access model. Users are entitled to use, reproduce, disseminate, or display the open access version of this article for non-commercial purposes provided that: the original authorship is properly and fully attributed; the Journal and Oxford University Press are attributed as the original place of publication with the correct citation details given; if an article is subsequently reproduced or disseminated not in its entirety but only in part or as a derivative work this must be clearly indicated. For commercial re-use, please contact journals.permissions@oxfordjournals.org 


\section{Decreased Depression}

Through the Transcendental Meditation Program

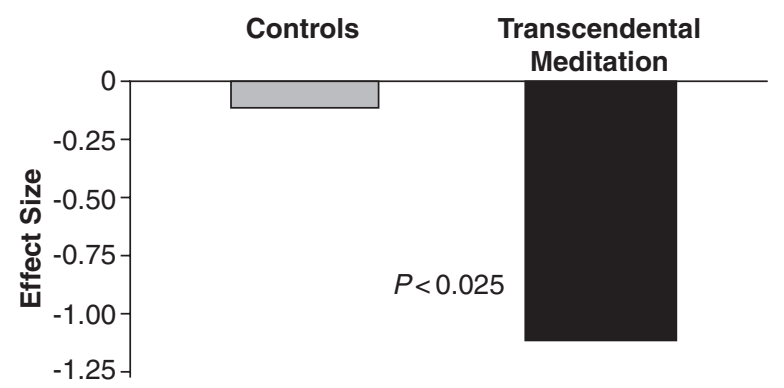

Figure 1. Patients suffering from post-traumatic stress problems who learned the Transcendental Meditation program showed significant reduction in depression after four months, in contrast to others who were randomly assigned to receive psychotherapy.

measure improvements related to stress decrease. In many TM studies, measured quantities are usually seen to continue changing for periods of many years, e.g. health expenditures have been seen to continue decreasing for several years (3).

Despite the small size of the study, its promise is such that it should be followed up on a larger scale. Iribarren et al. (1) paper made 11 references to war-related PTSD, including 8 to the Vietnam war. They pointed out that PTSD is increasing. About $8 \%$ of the population (over 20 million people) experience it at some point in their lives, with 6-8 million current sufferers. To reduce this level of suffering, and numbers of long-term out of work, hospitalized or on medication, and associated costs, any possible means of systematically reducing PTSD symptoms should be investigated.

The Transcendental Meditation program presents an attractive option. It has been investigated in over 600 studies of different kinds, carried out at over 100 research institutions in 30 countries (4-8). Variables seen to improve include underlying psycho-physiological changes as well as benefits to general, physical and mental health $(3,9)$. Reductions have been observed in spontaneous GSR's (10), anxiety (11), depression $(12)$, neuroticism $(13,14)$ and other indicators of stress $(15)$. It increases power (16-18) and cortical coherence $(19,20)$ in alpha frequencies, indicative of inner peace and lack of stress.

Modern neuroscience considers decreased brain wave coherence indicative of decreased integration and effectiveness of brain function. In the Virtual Scanning System of Assessment and Treatment (21), such cortical coherence is directly associated with the kind of poor physical, mental and emotional health associated with PTSD, and restoring coherence is a major aim of its system of flashing light color therapy (22). TM's systematic increase of coherence suggests that it can restore normal brain function after damage caused by trauma and unresolved after-effects.

\section{Acknowledgment}

I would like to acknowledge conversations with David Orme-Johnson and Dr Elena Ewing; also the financial assistance of Stephanie Hankey, and the University of Pune, which made this work possible.

\section{References}

1. Iribarren J, Prolo P, Neagos N, Chiappelli F. Post-traumatic stress disorder: evidence-based research for the third millennium. Evid Based Complement Alternat Med 2005;2:503-12.

2. Brooks J, Scarano H. Transcendental meditation in the treatment of post-Vietnam adjustment. J Counsel Dev 1990;64:212-5.

3. Herron RE, Hillis $\mathrm{S}$. The impact of the transcendental meditation programme on government payments to physicians in Quebec. Am J Health Promot 1996;10:208-16.

4. Orme-Johnson DW, Farrow JT (eds). Scientific Research on the Transcendental Meditation Program; Collected Papers, Volume 1. Rheinweiler, West Germany, MERU Press, 1977.

5. Chalmers RA, Clements G, Schenkluhn H, Weinless M (eds). Scientific Research on Maharishi's Transcendental Meditation and TM-Sidhi Program: Collected Papers, Volume 2. Vlodrop, The Netherlands, MVU Press, 1989.

6. Chalmers RA, Clements G, Schenkluhn H, Weinless M (eds). Scientific Research on Maharishi's Transcendental Meditation and TM-Sidhi Program: Collected Papers, Volume 3. Vlodrop, The Netherlands, MVU Press, 1989.

7. Chalmers RA, Clements G, Schenkluhn H, Weinless M (eds). Scientific Research on Maharishi's Transcendental Meditation and TM-Sidhi Program: Collected Papers, Volume 4. Vlodrop, The Netherlands, MVU Press, 1989.

8. Wallace RK, Orme-Johnson DW, Dillbeck M (eds). Scientific Research on Maharishi's Transcendental Meditation Program; Collected Papers, Volume 5. Fairfield, Iowa: MIU Press, 1991.

9. Orme-Johnon DW, Herron RE. An innovative aproach to reducing medical care utilization and expenditures. Am J Manag Care 1997;3:135-44.

10. Orme-Johnson DW. Autonomic stability and transcendental meditation. Psychosom Med 1973;35:341-9.

11. Eppley K, Abrams A, Shear J. Differential effects of relaxation techniques on trait anxiety: a meta-analysis. J Clin Psychol 1989;45:957-74.

12. Geisler M. Therapeutische Wirkungen der Transzendentalen Meditation auf drogenkonsumenten. Zeitschrift fur klinische Psychologie 1978;7: 235-55.

13. Abrams AI, Siegel LM. The transcendental meditation program and rehabilitation at Folsom State prison: a cross-validation study. Crim Justice Behav 1978;5:3-20.

14. Abrams AI, Siegel LM. Transcendental meditation and rehabilitation at Folsom prison: response to a critique. Crim Justice Behav 1979;6: 13-21.

15. Maclean CRK, Walton KG, Wenneberg SR, Levitsky DK, Mandarino JP, Waziri R, et al. Effects of the transcendental meditation program on adaptive mechanisms: changes in hormone levels and responses to stress after 4 months of practice. Psychoneuroendocrinology 1997;22:277-95.

16. Wallace RK. Physiological effects of transcendental meditation. Science 1970;167:1751-4.

17. Banquet JP. Spectral analysis of the EEG in meditation. Electroencephalogr Clin Neurophysiol 1973;35:143-351.

18. Krahne W, Taneli B. EEG and transcendental meditation. Pflugers Archiv 1975;190 (Suppl 359): R95.

19. Badawi K, Wallace RK, Orme-Johnson DW, Rouzere A.-M. Electrophysiologic characteristics of respiratory suspension periods occurrng during the practice of the transcendental meditation program. Psychosom Med 1984;46:267-76.

20. Yamamoto S, Kitamura Y, Yamada N, Nakashima Y, Kuroda S. Medial profrontal cortex and anterior cingulate cortex in the generation of alpha activity induced by transcendental meditation: a magnetoencephalographic study. Acta Med Okayama 2006;60:51-8.

21. Ewing G, Ewing E, Hankey A. Virtual scanning: a new method of health assessment and treatment. Part I: Assessment. J Alt Comp Med (in press).

22. Grakov I. Description of virtual scanning system for operators. Mimex, Sochi, Russia 2002a. English translation available at http://www. montague-diagnostics.co.uk/files/Grakov/Article7.pdf.

Received May 5, 2006; accepted May 26, 2006 


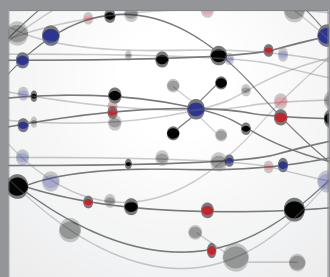

The Scientific World Journal
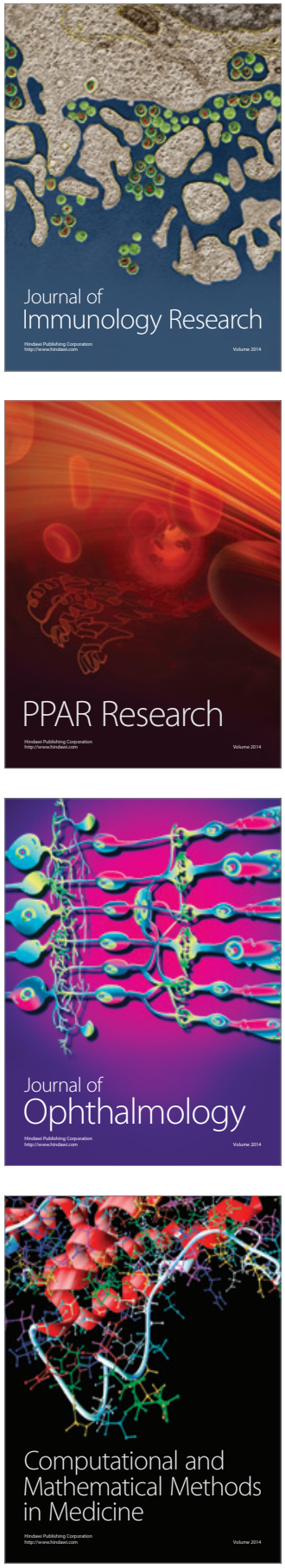

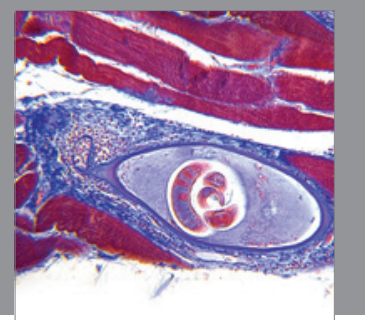

Gastroenterology

Research and Practice
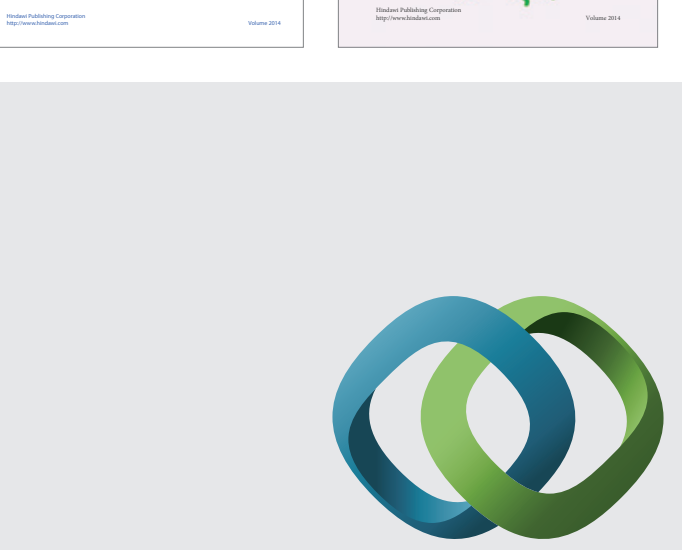

\section{Hindawi}

Submit your manuscripts at

http://www.hindawi.com
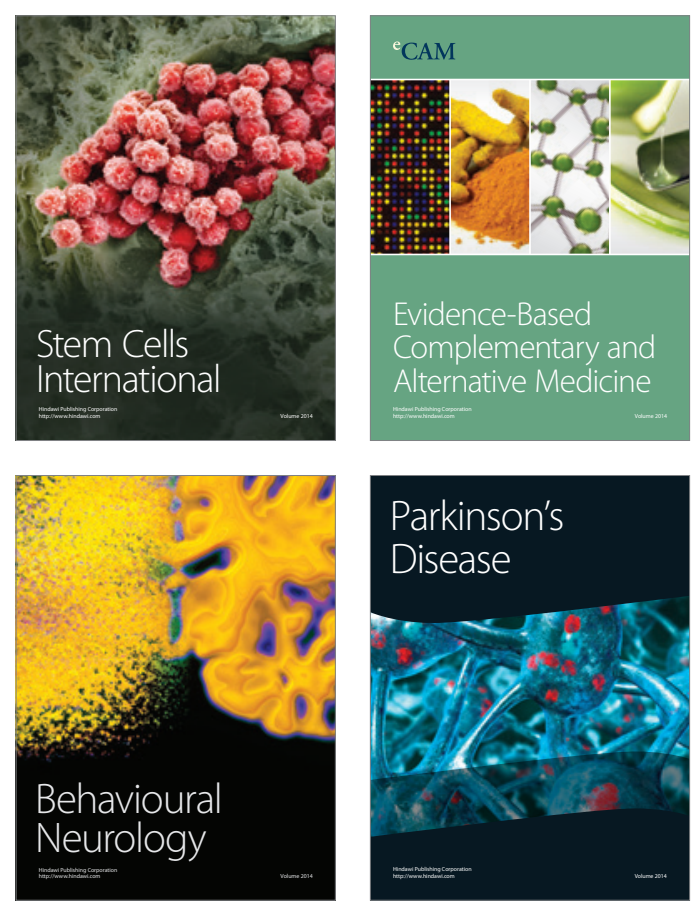

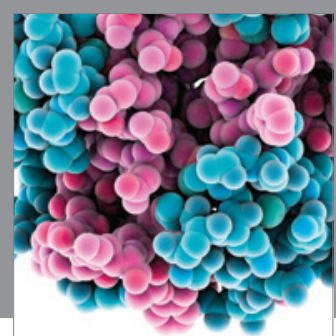

Journal of
Diabetes Research

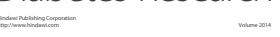

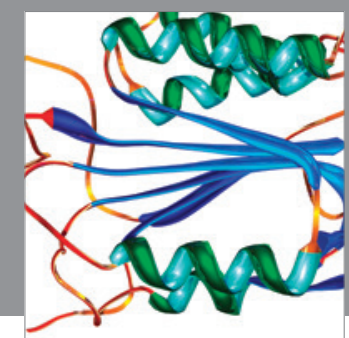

Disease Markers
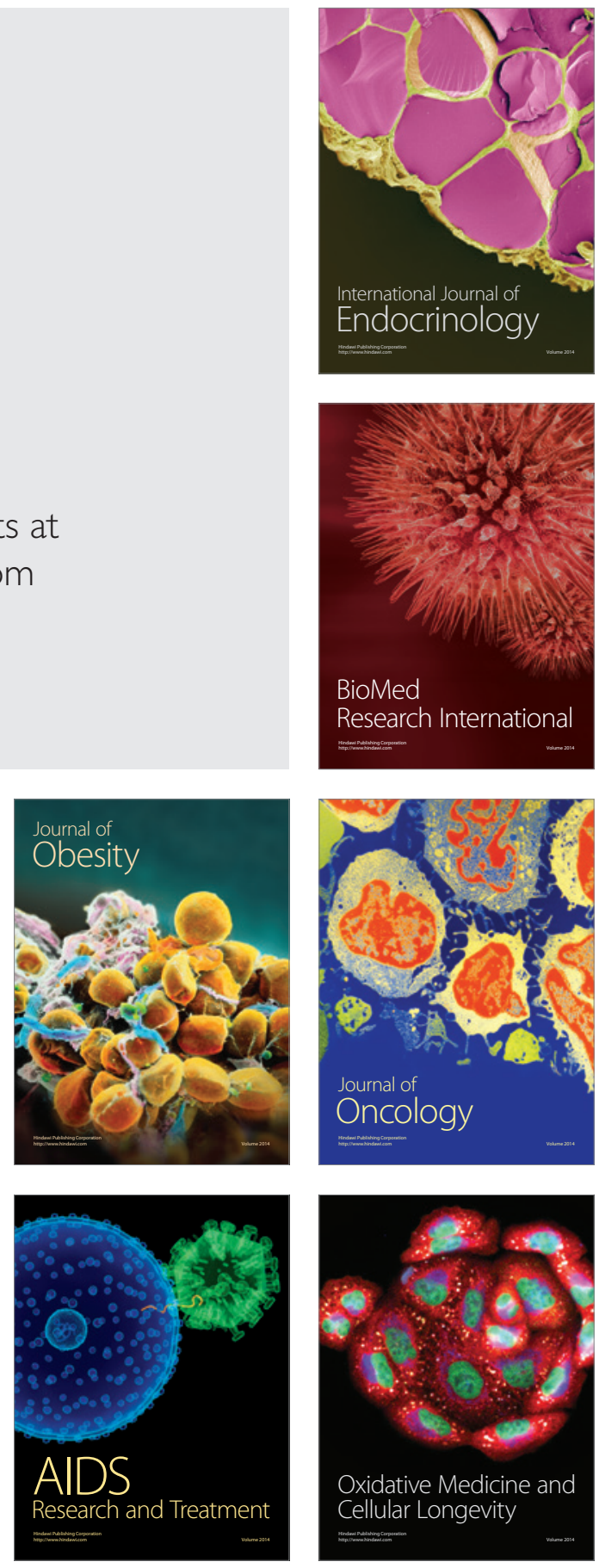